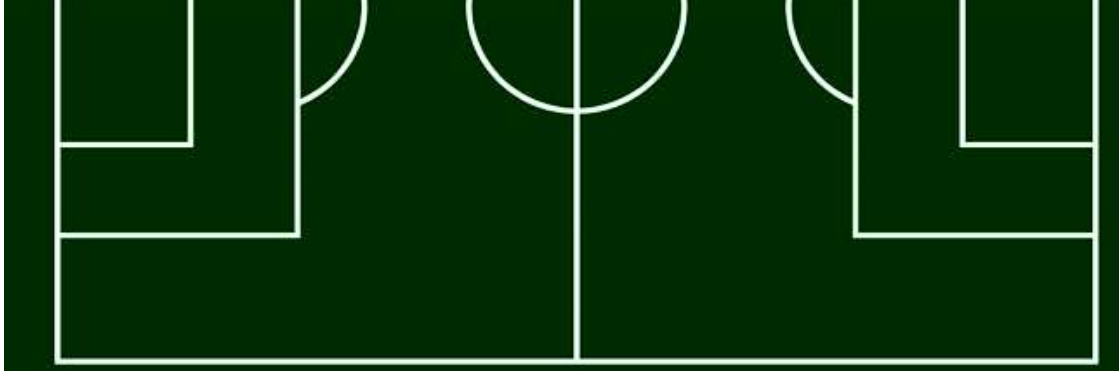

\title{
Investigación universitaria de Primera División
}

\author{
El Centro de Investigación del Deporte \\ asesora a los jugadores del Elche CF
}

\section{. Alicia de Lara | Lorena Santos}

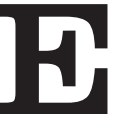

I objeto del convenio firmado entre la Universidad Miguel Hernández $(\mathrm{UMH})$ de Elche y el Elche Club de Fútbol (CF) es desarrollar la cooperación mutua, de forma que exista una transferencia de la labor formativa e investigadora al tejido deportivo. El acuerdo se plasma en el apoyo científico por parte de los investigadores del Centro de Investigación del Deporte (CID) de la $U M H$ a los deportistas y entrenadores de la plantilla del Elche CF. Como explica el director del Centro, Eduardo Cervelló, se trabaja para prevenir el riesgo de lesión de los jugadores y para ofrecer al cuerpo técnico información que le permita el ajuste de su entrenamiento.

"El CID pone al servicio del equipo sus conocimientos, lo que supone elevar el nivel de la preparación física a la excelencia. Los resultados son muy positivos y, prueba de ello, es que una temporada más se prolonga la colaboración entre ambas instituciones en esta faceta", apunta el presidente del Club., José Sepulcre. Además, hace hincapié en la buena acogida de este programa, iniciado en 20ll, por parte de la primera y segunda plantilla: "Me consta que cada temporada los profesionales están avanzando en este trabajo hacia un nivel muy alto de mejora del rendimiento". De esta manera, los miembros del cuerpo técnico están en permanente contacto con los investigadores y responsables del CID.

Por su parte, el preparador del Elche CF, José Mascarós, señala que las pruebas físicas iniciales practicadas por el primer equipo en la UMH fueron muy dinámicas y que los jugadores las superaron con éxito. El preparador físico destaca tanto las pautas proporcionadas por los investigadores para la prevención de lesiones, como las pruebas de esfuerzo y consumo de oxígeno que, según apunta, les permiten diseñar entrenamientos de forma individualizada y minuciosa.

En este sentido, el profesor del Área de Educación Física y Deportiva de la UMH Francisco Ayala explica que en el procedimiento se establece un perfil lesivo de cada jugador. Una valoración del estado físico, psicológico y social de los deportistas para que sus entrenadores y médicos puedan establecer objetivos específicos. Ayala añade que este trabajo incluye el estudio del rango de movimiento; la estabilidad dinámica; la fuerza del tronco y la fuerza cinética de la rodilla. Por último, se llevan a cabo pruebas de aducción y abducción de cadera para determinar el riesgo de lesión en la musculatura aductora y de la pubalgia.

Antes de las pruebas, se lleva a cabo un pesaje y un tallaje y, después, un calentamiento de 16 ejercicios que intercalan la carrera > 

Pruebas médicas de los jugadores

del Elche CF $\mid$ Daniel Madrigal

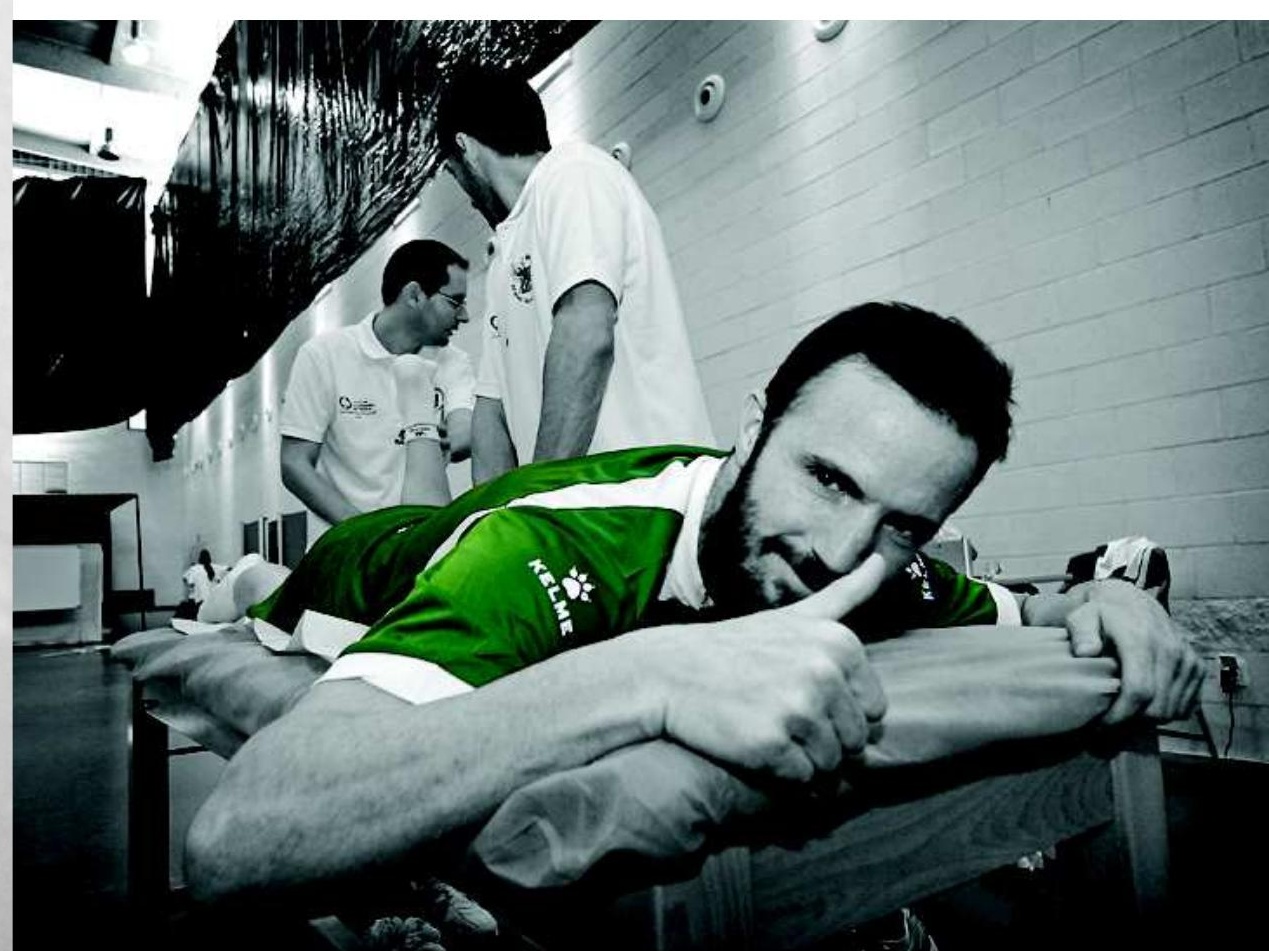

\section{Voces}

\section{franjiverdes}

El espacio radiofónico "Voces franjiverdes", que se emite en la Radio de la Universidad Miguel Hernández (UMH) de Elche, ha iniciado este curso su nueva temporada con una entrevista al presidente del Elche CF José Sepulcre, quien aseguró que su máxima prioridad es consolidar al equipo en la primera división, con jugadores propios y mantener un puesto entre los diez primeros de la tabla.

El programa universitario es un análisis en profundidad y de primera mano de toda la actualidad del Elche CF, desde el primer equipo hasta el fútbol base, pasando por el filial, las secciones, los clubes convenidos, las peñas y los veteranos. Se emite todos los lunes y viernes de 14:10 a 15:00 horas de la mano del licenciado en Periodismo por la UMH Antonio Chaves. 